\title{
Intake of man-made radionuclides due to food consumption by the population of different age groups
}

\author{
E. G. Metlyaev \\ Burnasyan Federal Medical Biophysical Centre, Russia
}

\begin{abstract}
To assess the public's internal doses due to radionuclide intake via food, data on radioactive substance content in foods and on per capita consumption of the particular foodstuffs, i.e., on food patterns of the population of the particular region are used. The food patterns depend considerably on social conditions, national special features and habits etc. Generally, it is rather stable. When evaluating contamination of the food ration with radioactive isotopes, prime attention should be paid to the critical groups of foods, i.e., those foods, which put the highest contribution of isotopes. The inspections show that meat and milk are critical foodstuffs, according to ${ }^{90} \mathrm{Sr}$ and ${ }^{137} \mathrm{Cs}$ intake, for residents of the Moscow region. The critical age group, i.e., such groups whose dose due to internal radiation exposure induced by ${ }^{90} \mathrm{Sr}$ and ${ }^{137} \mathrm{Cs}$ intake via foods is the highest, is children in the age range of $12-17$ years.

Keywords: foodstuffs, dose, man-made radionuclides, consumption, intake, critical group offoods, critical age group.
\end{abstract}

\section{Introduction}

Global fallout of radioactive products of nuclear explosions on-site in the Moscow region has been under observation since the latter part of the 1950s.

Firstly, the investigations were limited to the definition of concentration and isotope composition of radioactive aerosols in the near-land atmospheric layer. Then, a more detailed study of the radiation situation in the area of Moscow became necessary. When methods of radiochemical analysis of the environmental media were developed, an opportunity occurred to identify ${ }^{90} \mathrm{Sr}$ and ${ }^{137} \mathrm{Cs}$ content. Introduction of gamma spectrometry methods allowed for 
identification of a more complex set of radioactive substances in the environmental media. Assimilation of methods for identification of radioactive substances in foods permitted assessment of radioactive intakes and to evaluate dose accumulated by the public. This dose is the prime criterion of the radiation situation assessment.

To evaluate doses due to man-made radionuclide intakes, the following tasks have been completed:

1. The prime foodstuffs have being gathered and analyzed in terms of the extent of radionuclide contamination.

2. The food patterns have been identified for the average Moscow resident.

3. ${ }^{90} \mathrm{Sr}$ and ${ }^{137} \mathrm{Cs}$ intakes via the food ration have been evaluated for different age groups.

4. Effective doses have been calculated for different age groups of population due to ${ }^{90} \mathrm{Sr}$ and ${ }^{137} \mathrm{Cs}$ intakes via foods.

It should be noted that these investigations were being performed at the same time as intensive tests of nuclear weapons over the 1950-60s; they also were being performed during the Chernobyl NPP accident in 1980s. Now, these researches are still relevant, because the metropolitan region is characterized by a high density of population, and by the presence of plants, the operation of which assumes involvement of radiation sources.

\section{Content of man-made radionuclides in foodstuffs}

To evaluate ${ }^{90} \mathrm{Sr}$ and ${ }^{137} \mathrm{Cs}$ content in foodstuffs included in the food intake of the Moscow population, findings of direct studies performed in the FMBC over 2000-2007 have been considered. ${ }^{90} \mathrm{Sr}$ and ${ }^{137} \mathrm{Cs}$ content in foodstuffs over the period of examination are practically at the same level and vary over the range of statistic deviation, including foodstuffs from regions affected by trivial contamination resulting from the Chernobyl NPP accident (Ryazan, Kursk, and Tula areas).

Table 1 includes mean levels of ${ }^{137} \mathrm{Cs}$ and ${ }^{90} \mathrm{Sr}$ content over the period under examination.

It should be noted that in cities, averaging of values is also performed concerning the contribution of ${ }^{90} \mathrm{Sr}$ and ${ }^{137} \mathrm{Cs}$ into the ration of urban residents via potato, vegetables, meat and other local foodstuffs. This is because of food distribution over the network of urban markets or trade networks (by means of consignments) from different farms. The system of food supply also impacts significantly on ${ }^{90} \mathrm{Sr}$ and ${ }^{137} \mathrm{Cs}$ content in the ration of urban residents. This fact results in a larger contribution of foodstuffs accepted from other regions within the host-based supply system into the ration of urban residents through reducing quotas of local foodstuffs, so, levels of ${ }^{90} \mathrm{Sr}$ and ${ }^{137} \mathrm{Cs}$ content in the ration of urban residents are more stable $\mathrm{n}$, generally, much lower, than in the ration of farm residents [1].

At the moment of publishing this paper, data from the annual radiation hygienic passport of Moscow territory over 2008 has become known [2]. This 
document is being prepared with the participation of the Moscow administration. Data from the radiation hygienic passport of Moscow are used in the course of preparation of the radiation hygienic passport of the Russian Federation.

This table shows that data of the radiation hygienic passport over 2008 are in good compliance with data obtained in the FMBC over the previous period (2000-2007).

Table 3 includes permissible levels of ${ }^{90} \mathrm{Sr}$ and ${ }^{137} \mathrm{Cs}$ content in foodstuffs. These levels are regulated according to the national regulative document SanPiN 2.3.2.1078-01 "Hygienic requirements for safety and food significance of foodstuffs" [3].

Table 1: $\quad$ Mean ${ }^{137} \mathrm{Cs}$ and ${ }^{90} \mathrm{Sr}$ content in foodstuffs in the area of Moscow over $2000-2007, \mathrm{~Bq} / \mathrm{kg}$ [1].

\begin{tabular}{|c|c|c|}
\hline Foods & ${ }^{137} \mathrm{Cs}$ & ${ }^{90} \mathrm{Sr}$ \\
\hline Bread and cereal products & $\begin{array}{c}0.26 \\
(0.01-0.52) \\
n=21\end{array}$ & $\begin{array}{c}0.09 \\
(<0.02-0.61) \\
n=21\end{array}$ \\
\hline Milk and dairy & $\begin{array}{c}0.39 \\
(0.04-0.56) \\
n=133\end{array}$ & $\begin{array}{c}0.07 \\
(0.02-0.24) \\
n=102 \\
\end{array}$ \\
\hline Meat and meat products & $\begin{array}{c}0.32 \\
(0.03-0.48) \\
n=57\end{array}$ & $\begin{array}{c}0.14 \\
(<0.01-0.24) \\
n=57\end{array}$ \\
\hline Potato & $\begin{array}{c}0.20 \\
(<0.04-0.38) \\
n=11\end{array}$ & $\begin{array}{c}0.06 \\
(0.04-0.10) \\
n=11\end{array}$ \\
\hline Vegetables and melons & $\begin{array}{c}0.11 \\
(0.05-0.18) \\
n=12\end{array}$ & $\begin{array}{c}0.09 \\
(0.05-0.11) \\
n=12\end{array}$ \\
\hline Fish and fish products & $\begin{array}{c}0.32 \\
(0.16-0.60) \\
n=68\end{array}$ & $\begin{array}{c}0.14 \\
(0.10-0.77) \\
n=68\end{array}$ \\
\hline Fruits and berries & $\begin{array}{c}0.18 \\
(0.05-0.06) \\
n=7\end{array}$ & $\begin{array}{c}0.14 \\
(0.04-0.19) \\
n=7\end{array}$ \\
\hline Mushrooms & $\begin{array}{c}26.84 \\
(8.0-5.8) \\
n=5 \\
\end{array}$ & $\begin{array}{c}0.75 \\
(0.10-0.23) \\
n=5\end{array}$ \\
\hline Tea & $\begin{array}{c}2.0 \\
(3.0-4.9) \\
n=4\end{array}$ & $\begin{array}{c}5.2 \\
(2.9-8.3) \\
n=4\end{array}$ \\
\hline Drinking water ${ }^{*}$ & $\begin{array}{c}0.001 \\
n=4\end{array}$ & $\begin{array}{c}0.002 \\
n=4\end{array}$ \\
\hline
\end{tabular}


Table 2: $\quad$ Specific activity of radioactive substances in foodstuffs in Moscow over $2008, \mathrm{~Bq} / \mathrm{kg}[1]$.

\begin{tabular}{|l|c|c|}
\hline Foodstuffs & ${ }^{137} \mathrm{Cs}$ & ${ }^{90} \mathrm{Sr}$ \\
\hline Bread and cereal products & 0.28 & 0.09 \\
\hline Milk and dairy & 0.39 & 0.07 \\
\hline Meat and meat products & 0.32 & 0.14 \\
\hline Potato & 0.20 & 0.06 \\
\hline Fish and fish products & 0.32 & 0.14 \\
\hline Mushrooms & 8.00 & 0.23 \\
\hline
\end{tabular}

Table 3: $\quad$ Permissible levels of ${ }^{90} \mathrm{Sr}$ and ${ }^{137} \mathrm{Cs}$ content in the prime foodstuffs, $\mathrm{Bq} / \mathrm{kg}$.

\begin{tabular}{|l|c|c|}
\hline Foodstuffs & ${ }^{137} \mathrm{Cs}$ & ${ }^{90} \mathrm{Sr}$ \\
\hline Bread and cereal products & 40 & 20 \\
\hline Milk and dairy & 100 & 25 \\
\hline Meat & 160 & 50 \\
\hline Potato & 120 & 40 \\
\hline Vegetables and melons & 120 & 40 \\
\hline Fish & 130 & 100 \\
\hline Fruits and berries & 40 & 30 \\
& $160^{*}$ & $60^{*}$ \\
\hline Mushrooms & 500 & 50 \\
\hline *Wild berries & \multicolumn{2}{|c}{} \\
\hline
\end{tabular}

So, radionuclide content in the prime foods are within $1 \%$ of permissible level of ${ }^{90} \mathrm{Sr}$ and ${ }^{137} \mathrm{Cs}$ content in the prime foodstuffs.

\section{Consumption and intake of man-made radionuclides by Moscow residents via foods}

Analysis of food consumption within husbandries (all households) is based on the data of the Federal State Statistical Service over the period 2000-2007. Assortment and specific significance can vary considerably depending upon a number of factors, such as: food patterns, pathways and intensity of food contamination, induced by natural conditions, etc. Generally, food patterns are rather stable.

Table 4 includes data on annual food consumption for the average consumer over the years examined in Moscow.

To obtain data on consumption of the prime foodstuffs by the population of different age groups, data on factual food raw material (meal) consumption 
required to be transferred to data on finished product (bread) consumption. With this purpose, coefficients of food transmission were used [4].

Then, annual consumption was used to calculate consumption of the prime foodstuffs for the particular age groups. With this purpose, food patterns have been developed for 7 prime food groups with indication of their consumption in $\mathrm{kg} /$ day units.

The following age groups were under consideration: 1-2 years old; from 2 to 7; from 7 to 12; from 12 to 17; adults (older than 17). International Commission on Radiological Protection proposed these age groups and they were included in the "International Basic Safety Standards for Protection against ionizing Radiation and for the Safety of Radiation Sources" and the national regulative documents - NRB-99, OSPORB-99 [5-7]. For persons from each group, the averaged over this group food consumption is assumed in the course of effective dose calculation ( $\mathrm{kg} /$ day).

Table 4: Annual consumption of the prime foods in husbandries of Moscow according to findings of selective inspection of domestic economic budgets performed by the Goscomstat of Russia over 2000-2007, for the average consumer, $\mathrm{kg}$.

\begin{tabular}{|l|c|}
\hline Foodstuffs & Amount \\
\hline Bread and cereal products & 90.3 \\
\hline Milk and dairy & 300.1 \\
\hline Potato & 57.9 \\
\hline Vegetables and melons & 86.9 \\
\hline Fruits and berries & 61.9 \\
\hline Meat and meat products & 85.9 \\
\hline Fish and fish products & 18.7 \\
\hline
\end{tabular}

Table 5 includes data on consumption of the prime food groups by the persons from the particular age groups in Moscow over 2003, kg/day. In parentheses, quota of averaged daily ration has been calculated, which generally complies with physiological food standards established for these ages [8].

Table 6 includes data on the mean intake of ${ }^{90} \mathrm{Sr}$ and ${ }^{137} \mathrm{Cs}$ via the food ration by the population from different age groups. This table shows that the highest ${ }^{90} \mathrm{Sr}$ and ${ }^{137} \mathrm{Cs}$ intake is typical for milk and dairies, as well as for meat and meat products.

\section{Doses to Moscow residents induced by man-made radionuclides}

In calculation of effective internal doses due to ${ }^{90} \mathrm{Sr}$ and ${ }^{137} \mathrm{Cs}$ intakes via foods and drinking water by Moscow residents, annual radionuclide intakes via foods for different age groups of residents and dose coefficients for ${ }^{90} \mathrm{Sr}$ and ${ }^{137} \mathrm{Cs}$ for each age group [4] were used. 


\begin{tabular}{|c|c|c|c|c|c|c|c|c|}
\hline 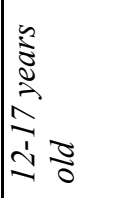 & 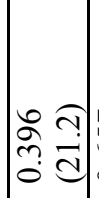 & 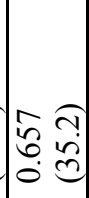 & $\mid \begin{array}{cc}\hat{N} & 0 \\
0 & 0 \\
0 & 0\end{array}$ & 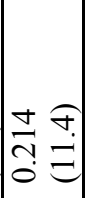 & 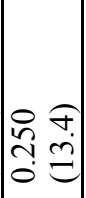 & 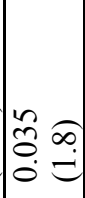 & 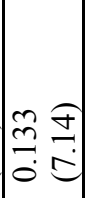 & \begin{tabular}{l}
$\widetilde{D}$ \\
$\infty$ \\
\hdashline
\end{tabular} \\
\hline 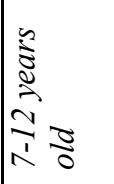 & 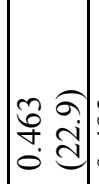 & $\mid \begin{array}{ll}0 & \widehat{\sigma} \\
\stackrel{d}{d} & \stackrel{d}{d}\end{array}$ & 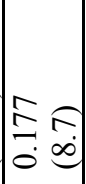 & 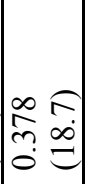 & 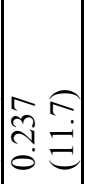 & 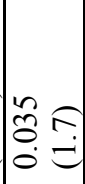 & 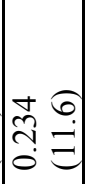 & 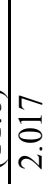 \\
\hline 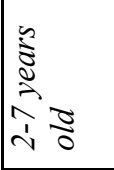 & $\left.\begin{array}{ll}\infty & f \\
\hdashline & \ddots \\
0 & \Xi\end{array}\right]$ & $\mid \begin{array}{ll}\overrightarrow{1} & 0 \\
0 & \dot{y} \\
0 & \end{array}$ & $\overrightarrow{\widetilde{N}} \approx$ & 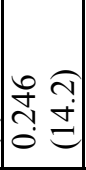 & 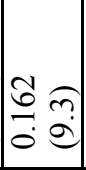 & 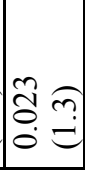 & 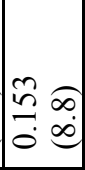 & 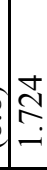 \\
\hline 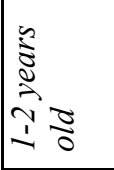 & $\left.\begin{array}{l}n \\
0 \\
0\end{array}\right]$ & $\mid \begin{array}{cc}\overrightarrow{1} & \widehat{a} \\
0 & \dot{0} \\
0 & 0\end{array}$ & $\begin{array}{ll}0 & \\
\cdots & ? \\
0 & ?\end{array}$ & $\left.\mid \begin{array}{ll} & \ddots \\
0 & 0 \\
0 & 0\end{array}\right]$ & 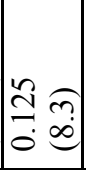 & 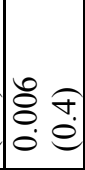 & $\left.\begin{array}{ll}1 & \\
0 & 0 \\
0 & 0 \\
0 & 0\end{array}\right]$ & $\stackrel{m}{\stackrel{m}{g}}$ \\
\hline 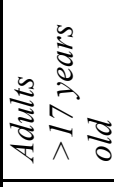 & $\left.\begin{array}{ll}m & - \\
\vec{t} & \vdots \\
0 & 0\end{array}\right]$ & 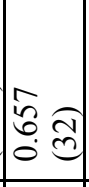 & $\mid \begin{array}{ll}2 & 0 \\
\partial & 0 \\
0 & 0\end{array}$ & 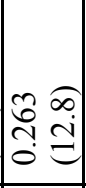 & 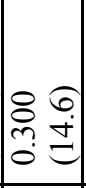 & $\left.\mid \begin{array}{ll}\infty & \\
0 & 0 \\
0 & 0 \\
0 & d\end{array}\right]$ & 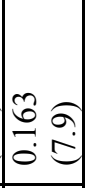 & $\hat{n}$ \\
\hline 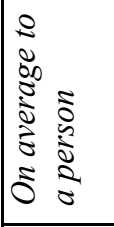 & 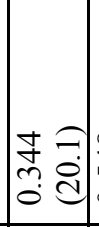 & $\begin{array}{l}\infty \\
0 \\
0 \\
0\end{array}$ & 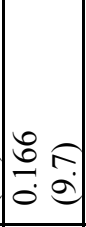 & 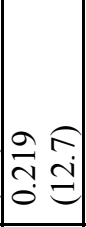 & 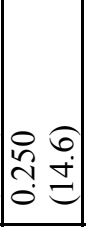 & $\mid \begin{array}{ll}\infty & \\
0 & 0 \\
0 & 0 \\
0 & d\end{array}$ & 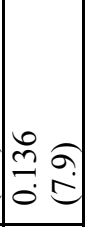 & $\stackrel{F}{F}$ \\
\hline $\mid \begin{array}{l}\sqrt{1} \\
0 \\
0 \\
0 \\
0 \\
0 \\
0 \\
0\end{array}$ & 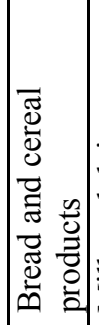 & 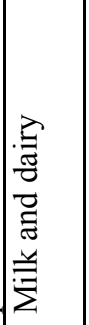 & 龸 & 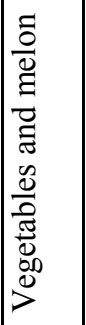 & $\sum^{\vec{\Xi}}$ & 氧 & 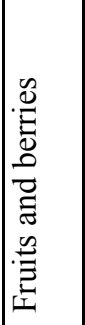 & 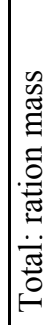 \\
\hline
\end{tabular}




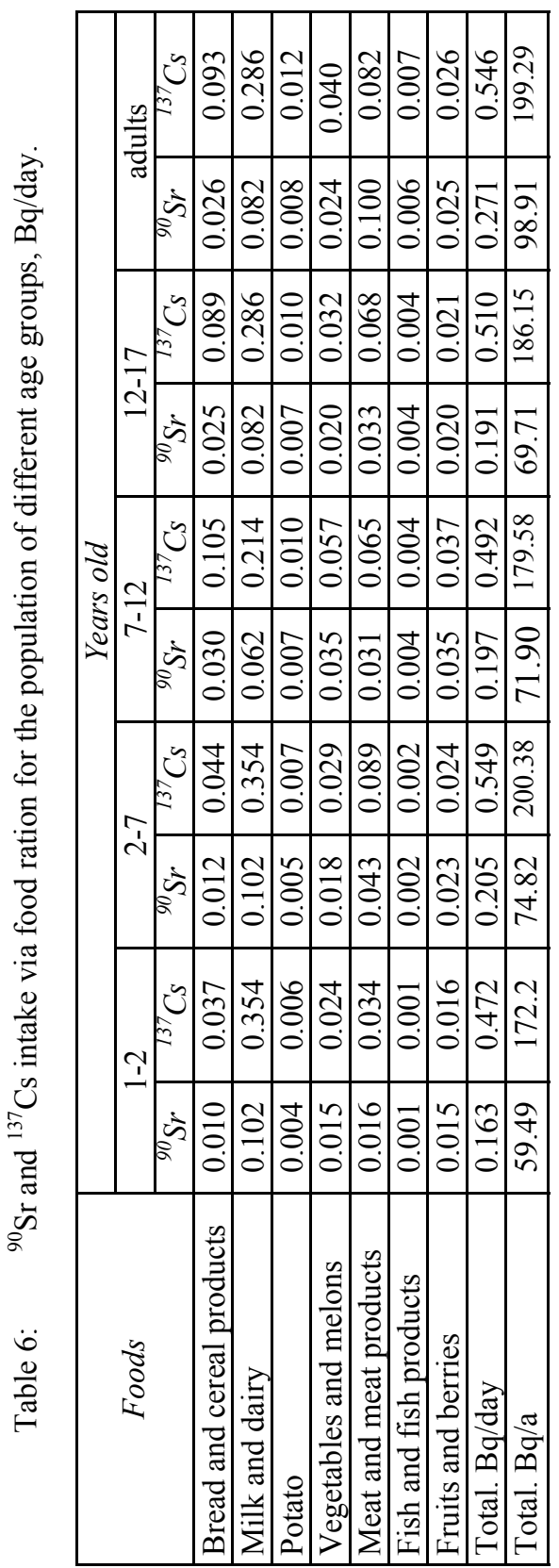


Table 7: $\quad$ Effective internal doses induced by food consumption, due to ${ }^{90} \mathrm{Sr}$ and ${ }^{137} \mathrm{Cs}$ intake for different age groups of Moscow residents over the period $2000-2007$, on average, $\mu \mathrm{Sv} / \mathrm{a}$.

\begin{tabular}{|l|c|c|c|}
\hline Age, years & ${ }^{90} S r$ & ${ }^{137} \mathrm{Cs}$ & $\Sigma$ \\
\hline $1-2$ & 3.60 & 1.56 & 5.16 \\
\hline $2-7$ & 2.95 & 1.54 & 4.49 \\
\hline $7-12$ & 4.1 & 1.5 & 5.6 \\
\hline $12-17$ & 5.21 & 1.7 & 6.91 \\
\hline Adults & 2.33 & 2.24 & 4.6 \\
\hline
\end{tabular}

At that, calculation has been performed in terms of average consumption over each age group.

Table 7 includes effective internal doses to Moscow residents due to ${ }^{137} \mathrm{Cs}$ and ${ }^{90} \mathrm{Sr}$ intakes via the food ration over the period $2000-2007$, on average.

The table shows that the highest internal dose due to ${ }^{137} \mathrm{Cs}$ and ${ }^{90} \mathrm{Sr}$ intake by Moscow residents is registered in the group of children of $12-17$ years old. This age group is critical according to intake of man-made radionuclides.

\section{Conclusion}

The inspections performed results in the following conclusions.

The food patterns of Moscow residents are stable. The prime groups of foods forming doses to the public include milk and dairies, as well as meat and meat products. Consumption of the prime foods over the period under inspection is at the same level within the range of the statistical deviation. ${ }^{137} \mathrm{Cs}$ and ${ }^{90} \mathrm{Sr}$ content in foodstuffs are at the level of the recent years data and are not higher than $1 \%$ of permissible level of their content in foodstuffs. Total effective dose to adult residents due to ${ }^{137} \mathrm{Cs}$ and ${ }^{90} \mathrm{Sr}$ intake, on average, over the period under examination is $4.6 \mu \mathrm{Sv} / \mathrm{a}$; dose to the critical group of the public (children of 12 - 17 years old) is $6.9 \mu \mathrm{Sv} / \mathrm{a}$; these are much lower than contribution of natural radionuclides, such as ${ }^{210} \mathrm{~Pb}$ and ${ }^{226} \mathrm{Ra}(50 \mu \mathrm{Sv} / \mathrm{a})$.

Findings of inspections performed allow evaluation of real contribution of man-made radionuclides into internal public dose and give knowledge on ${ }^{90} \mathrm{Sr}$ and ${ }^{137} \mathrm{Cs}$ intake with foods depending upon age of persons under inspection.

\section{References}

[1] A N Marej, R M Barkhoudarov, N Ya Novikova Global Fallout of ${ }^{137}$ Cs and the Human. Atomizdat: Moscow, 1974. 
[2] Radiation hygienic passport of Moscow Territory over 2008. GUP MosNPO "Radon": Moscow 2009.

[3] SanPiN 2.3.2.1078-01 Hygienic Requirements for Safety and Food Significance of Foodstuffs Minzdrav of Russia: Moscow, 2001.

[4] Consumption of foods from husbandries over 2003 (according to results of selective inspections of domestic economic budgets), Goscomstat of Russia: Moscow, 2004.

[5] International Basic Safety Standards for Protection against ionizing Radiation and for the Safety of Radiation Sources, International atomic energy agency, Vienna, 1994.

[6] SP 2.6.1.758-99 Radiation Safety Standards (NRB-99), Department of Gossanepidnadzor of Russia: Moscow, 1999.

[7] SP 2.6.1.799-99 Main Sanitary Rules for Radiation Safety (OSPORB-99), Department of Gossanepidnadzor of Russia: Moscow, 1999.

[8] NK Shandala, N Ya Novikova, FK Levochkin, AV Titov ea. Research Report of SRC-IBPh. Assessment of internal doses to the residents of Moscow, due to intake of Strontium-90 and Cesium-137 (90Sr and 137Cs) via foodstuffs and drinking water. // M.:-2006-21p. 